\title{
Doing Something About The Future
}

\author{
Rolfe Tomlinson
}

\author{
$\mathrm{SR}-80-1$ \\ September 1980 \\ Reprinted from the \\ Journal of the Operational \\ Research Society
}

Volume 31(1980) 
Status Reports describe the progress of IIASA research. However, the views and opinions they express are not necessarily those of the Institute or the National Member Organizations that support it.

Reprinted with permission from the Journal of the Operational Research Society $31: 467-476,1980$.

Copyright $\odot 1980$ Operational Research Society Ltd. 


\section{FOREWORD}

The International Institute for Applied Systems Analysis (IIASA) conducts studies relating to problems in a number of areas of wide concern: energy, food and agriculture, human settlements and services, resources and environment, and management and technology, as well as analytic techniques required to address problems in these areas.

This paper discusses how such problems must be approached, and how Mr. Tomlinson used this approach to develop the program in the management and technology area at IIASA during his chairmanship.

This account is based on a talk given at the Annual Meeting of the Operations Research Society of the United Kingdom on 7 September 1979.

ALEC LEE

Chairman

Management and Technology Area 



\title{
Doing Something About the Future*
}

\author{
ROLFE TOMLINSON \\ National Coal Board, on secondment as Chairman, Management and Technology Area, \\ International Institute for Applied Systems Analysis, Laxenburg, Austria
}

\begin{abstract}
This paper is concerned with the need for more interdisciplinary, systems oriented, research directed towards major problems encountered by decision makers in industry and government; a need which is more difficult to meet in the face of traditional methods of organising knowledge and research. It emphasises the need to acknowledge the true complexity of the problems and the interactive nature of any effective research procedure. As an illustration, both of the need and the problems involved in meeting it, the development of a new program of research into problems of Management and Technology at the International Institute of Applied Systems Analysis, which is supported by seventeen nations of all political complexions, is analysed. The implication is that we can do something about the future, but we must be prepared to do.
\end{abstract}

THIs paper is one of a series in which the author has explored, from an empirical base, ${ }^{1-4}$ the nature of the process of operational research and systems analysis (ORASA). In particular, it is concerned with the need for a more positive attitude towards interdisciplinary systems oriented research. It is also, however, a pièce doccasion, with an important, though perhaps more ephemeral, secondary message. The occasion was the 1979 Operational Research Society conference, and the secondary message was a sequelrather than a response- - to two papers presented by Russ Ackof ${ }^{s, 6}$ at the previous year's conference. In those papers Ackoff warned that if certain trends- - towards computer dependence, technique worship and the general acceptance of the mores of hard, disciplinary science-developed in the U.K. as they had elsewhere (and there is evidence of such trends) then O.R. would fail to develop as a distinctive contributor towards the solution of the major complex problems of society. In short it would degenerate into yet another managerial speciality of minor importance. The arguments were not new in essence, but they were presented in such a forceful and direct way as to attract widespread attention. Ackoff was being prophetic, in the best traditions of Hebraic prophesy, and was prophesying doom, a doom which he hoped would yet be averted.

I believe that the doom which Ackoff and others like him have warned us of will be averted; not simply because people will have listened and changed their ways, but because the prophets have misread the signs. They have taken their evidence from what has been presented to them-largely in the form of papers and books; in the U.K. at least this is a small part of the truth. The reality of ORASA is not incarcerated in print - it is a living activity, mostly undertaken by in-house teams working in industrial, business and governmental organisations. A paper by Tobin, ${ }^{7}$ given at the conference, showed how the prophetic view was a travesty of the reality so far as his own team was concerned. Many others could have done so - I wish they had.

Even if the true state of affairs had been reported, the prophets would not necessarily have listened. In truth, it is not easy to explain exactly how the subject is developing in those places where it is most successful. I have for some years been puzzled by the reaction of some colleagues from other countries when I have described the relationship, as I had experienced it, between management in the National Coal Board and the O.R. scientists. (It is not so different from that in most successful teams in the U.K.). I thought at first that the reaction was that of polite disbelief, but $I$ now see it as being nearer to incomprehension. The kind of "action research" relationship which we have been developing over the years, and which is so well described by Hylton Boothroyd, ${ }^{8}$ is both puzzling and unscientific to those whose thought is still dominated by the "specialist/ consultant" paradigm. When you look below the surface, some of the work going on in

- Revised text of paper given at the Annual Meeting of the Operational Research Society, Stirling. Scotland, Friday, 7 September, 1979. 
in-house groups is as excitingly innovalive as that in Ackolis Social Systems Science team in Pennsylvania.

This does not mean that things are perfect, nor that the subject or its practitioners can stand still. Even if they were perfect now, we would have to change to meet the challenge of a very different future. We would still have to do something about the future. That is the prime message of this paper. But the secondary message is that we can do so on the basis of pride and confidence in some rather exceptional achievements so far. We have no cause for dismay or shame.

This paper then is concerned with doing something about the future. Before, however, we explore the question of what to do, we must say something about objectives. Let us start with an obvious statement, namely that the world within which we operate is extremely complex. In order to start to understand it we have tried to split it up into many fields of knowledge. Great progress in understanding has been nade in some of these fields, but even so we do not even pretend to have a comprehensive understanding of how the physical world, let alone Society, works. Those who adopt a less reductionist approach $\cdots$-the theologians and philosophers-have not made too much progress either. They have certainly not been able to reduce our understanding of the world and its social organisations to a few simple rules or paradigms

Now operational research, which is concerned with scientific intervention in this complex world, inevitably shares in the same degree of complexity. Why then do people think that they can describe operational research in terms of one simple paradigm or a small number of simple rules? There is no one paradigm for the forward development of operational research. There are no few simple principles that will adequately describe what we are trying to do. If ever there were - the subject would already be dead. We must accept the complexity of life. There are many ways forward, and we must refute any prophet who says that there is only one way.

Nevertheless many have felt the need to define our subject in simple terms; the attempts to do so abound in the literature. I have recently suggested ${ }^{4}$ that any true understanding must be built on an acceptance that any set of definitions that we might lay down are necessarily imperfect--there are always exceptions to such rules. At the best we can only define "near" truths. But I also pointed out that if these rear truths are taken as literal truths, they turn out not to be truths at all, but lies. And, since the most dangerous lies convince because they seem to be true, these near truths can easily turn into lies, very dangerous lies. In this sense, Ackoff may be said to have at the best put forward a "near" truth, and we are in danger of replying to him in like manner, with a dangerous lie. We must seek a way forward, but not down the road of oversimplification.

Perhaps the most dangerous simplification of all is the belief that one can draw a neat boundary round the subject, isolate ourselves from other thinkers and specialists, and develop a future on our own. We cannot. Such an idea denies the relationship we have developed in those teams where we have been most successful---since our successful work has been fundamentally interactive and cooperative. I would suggest that if we go forward we can only do so with others, and that the time has come for us to rethink our position in relation to what can best be described as the interdisciplinary systems movement. The best way to explain this is to draw on my recent experience at the International Institute for Applied Systems Analysis which may be said to be near the heart of this movement. I shall therefore briefly describe the Institute and its programme of work, and then discuss some of the problems we have had to overcome there in building up a research programme concerned with Management and Technology and which seem to be particularly relevant to my theme.

\section{THE INTERNATIONAL INSTITUTE FOR APPLIED SYSTEMS ANALYSIS}

The Institute was founded in 1972 after long negotiations starting from tentative proposals made by Kruschev and Johnson in 1966. The background idea was that, if detente 
were to mean anything, we should work together on some of the common problems that we shared. It is perhaps worth mentioning that one of the main problems in setting up the Institute was in deciding on a name. It was agreed that the Institute should be studying the complex decision problems, both global and universal, facing our highly developed societies. The British thought that Operational Research was the right titlebut elsewhere it often had such a narrow connotation that it was unacceptable. In the end, Applied Systems Analysis proved to be an acceptable phrase. (It has been suggested since the phrase was undefined, nobody could disagree with it).

The Institute now has 17 member countries from East and West Europe, North America and Japan. The U.S.S.R. and the U.S.A. are the major partners, each providing just over a quarter of the subscribed income and of the scientific staff. The other I5 countries are equal members both in their financial contributions and numbers of staff. (The average is about three scientists per member country, other than U.S.A. and U.S.S.R.).

Possibly the most important of all the decisions made in the initial negotiations was that IIASA should be a non-Governmental Institute. Non-Governmental means, quite simply, that the controlling Council does not consists of Government appointees, but rather representatives of the Academy of Sciences in the country concerned, or where this was not appropriate, of some specially-constituted scientific committee of equal status. Thus the Council member for the United Kingdom is currently the Treasurer of the Royal Society. This has turned out to be one of our greatest strengths because these bodies, whilst being influential, are extremely jealous of their independence and of their scientific reputation. This has relieved the Institute of many of the bureaucractic pressures that arise in governmental international organisations-for example, no scientific posts are earmarked for any one country. Currently, there are 75 scientists paid for out of the subscriptions of member countries; and about 20 scientists supported from other funds. The total budget at the moment is about $\$ 10$ million.

The Institute currently has six main research fields: Energy; Food and Agriculture: Resources and Environment, Human Settlements and Services; Management and Technology; and Systems and Decision Sciences. There is also work on Regional Development, and a major publishing programme.

Since no national Institutes of Applied Systems Analysis existed when IIASA was set up, it had to start from the beginning in deciding what work it could usefully undertake, and what its detailed objectives would be. This was particularly true in the Management and Technology Area, where the programme has been shaped only over the past two years. There are at least two good reasons for IIASA to have a research Area with this title. One is that an Institute of Applied Systems Analysis should be concerned with application. Applications occur only when one makes contact with those concerned in decision processes, and appropriate decisions are taken. Consequently, the overall team needs to contain people experienced in the interface between analysis and management, who know something about management and management processes. Secondly, if the Institute is concerned with the problems of the developed world, they must be aware that many of these problems, if not most of them, arise from or are accentuated by changes in technology or the problem of managing technology itself. So a programme in Management and Technology makes sense in principle; the question was to decide what it could be in practice. Three of the issues that we had to think through are of particular relevance to the general theme of this paper, and I shall therefore discuss them in turn.

\section{WHAT IS 'APPLIED'?}

One of the most important things we have had to think through is what we mean by "applied". This may appear to be an absurd question, but in a recent job application a candidate referred to "Used Mathematics" as one of his college subjects. (He might, I suppose, have said "second-hand", which raises the delightful image of salesmen selling mathematics as they do cars.) The point of this story is that in the context of mathemat- 
ics, "applied" does not necessarily mean "used". I studied at a University where applied mathematics is called "Natural Philosophy" and is only "applied" in the sense that it is concerned with the development of mathematical models of some physical reality. Sometimes the models may not be very exact, or it may be impossible to solve them exactlybut, in general, the understanding that is generated through the mathematical process is what matters. Some of our work at IIASA is applied only in this special sense. We are developing models which enable us to try and understand how complex, interrelated systems behave. We bring together a variety of methodological and technological experience from many countries; and then try to develop together, in conjunction with policymakers, an understanding of the behaviour of these particular kinds of complex systems. If we can achieve understanding, then that is a very real "applied" result.

(An aside may be of interest here. There is, and always has been, criticism of University courses in O.R. because they contained too much mathematics, which the students never subsequently used in practice. Now, if the only reason for teaching mathematical techniques is in order to enable people to undertake more elaborate calculations, then we probably do teach too much mathematics. On the other hand, it could equally be argued that the most important thing that you learn from Queueing Theory is not the method of solving the mathematics but an understanding of how queues behave. You can explore things using theory, and thus develop understanding, that you cannot in real life or even when using simulations. The same may be said with other mathematical formulations. The question thus moves from whether mathematics should be extensively taught to why, i.e. what the lecturer sets out to achieve. Is the time to be spent on teaching people methods of manipulation, or in giving them an understanding of how systems actually behave. If it is the latter, then the mathematical input may be justified.)

Having said this, in the subject area of Management and Technology we are primarily concerned, though not exclusively so, about doing work whose results can be "used". Certainly, the Council of the Institute are defining "applied" in this traditional manner. But if one accepts this definition of "applied", the very location of the Institute creates great difficulties. Vienna is after all, remotely located so far as most points of use in the national member countries are concerned. In fact, if you think about it, it is absurd to think that the Institute's work could, except in rare cases, be of direct use to policymakers or decision-makers. Rather it is the policy advisers that we can hope to help those actively in touch with the decision process who themselves are undertaking analysis, often with inadequate information and techniques. But before we proceed with this discussion, it is necessary to rehearse the way in thich O.R. and systems analysis really do make an impact on the decision-making process.

The traditional description of how the analyst helps management is illustrated in Figure 1. "There is an initial meeting between the manager and the analyst at which the symptoms which concern the manager are converted into a problem that the analyst thinks he can solve. (This meeting may, of course, become a dialogue over several meetings.) The analyst then takes the problem away, solves it, and proposes an implementable form of the solution to the manager. Who, of course, accepts it". This traditional description bears little relation to reality-for many reasons. Perhaps the most important reason is that it assumes that the problem remains unaltered-whether in reality or in the manager's perception. Even at this simplistic level, the true picture would

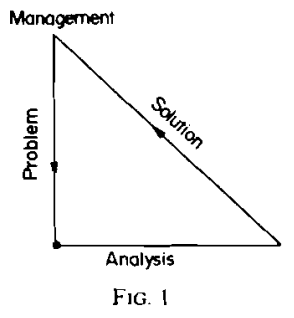




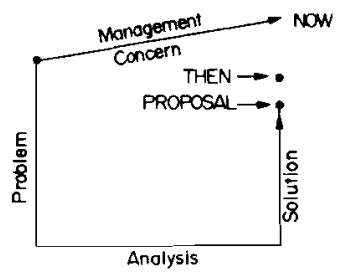

Fig. 2

be more like Figure 2. In fact, in the elapsed time both the managers' and analysts' perceptions are likely to alter, with the consequences that the analyst's solution is not relevant to the problem perceived by the manager.

Of course if you talk to any successful O.R. group you will find that these simplistic ideas do not bear any relation to what actually happens. The effective group behaves in the manner indicated by Figure 3 -in that the management process and the analytical process are continually overlapping all the time. The analysts, the ORASA* team, are not remote people that come in, talk to someone, take away the problem, and go back. They are there. They are part of the management team. Our "pure" scientific colleagues may enquire about what this does to objectivity - without usually very strong philosophical grounds for doing so-but it is the very heart of genuine implementation, or, as Boothroyd has described it, articulate intervention. The heart of all this is to understand that we are concerned with "process"-with the management process, the analytical process and their interaction. You may talk of problem identification, re-identification, re-reidentification-i.e. try to talk of it all as an incremental process. But we shall probably understand it all far better if we think in terms of continuous processes-if only because this forces us into a different mould of thought and makes us develop different kinds of models.

Now if these criticisms of the classical description of management/analyst interaction are valid, they have major implications with regard to the way in which a Research Institute can operate. The classical analogue would be as in Figure 4. It is an approach that might be valid for an Institute of Mathematics or Economics or Social Science, but certainly not for an Institute of Applied Systems Analysis. There are two reasons for this. One is that it ignores the continuity of interaction necessary for the effective solution of a systems problem. The other is that it separates the Institute from the real problem - which is always fatal in 'applied" work. In practice, following the Venn diagram of Figure 3 we may have two effective modes of operation (Figure $5(\mathrm{a})$ and (b)). In $5(\mathrm{a})$ management originally deal directly with the Research Institute which, as the solution develops, increasingly involves the analysts. This is a common mode and one which is often adopted by University based research teams. For organisational reasons it would be a difficult one to adopt at IIASA. But there are, in addition, some fundamental objections, particularly with regard to the 'inferior' position imposed on the analyst. I prefer the alternative approach, whereby the major management interaction remains with the analyst on the spot, and the researcher becomes an extension of his team, having

* Because it is impossible for me to make a distinction, in theory or practice, between Operational Research and Applied Systems Analysis 1 shall, from this point on use the abbreviation ORASA.

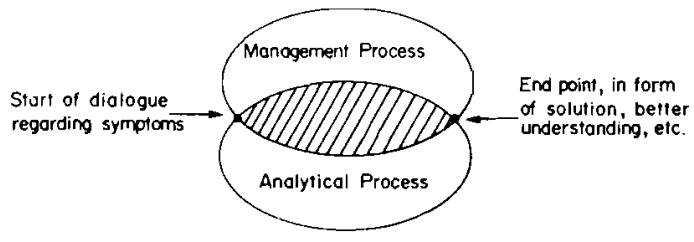

FIG. 3 


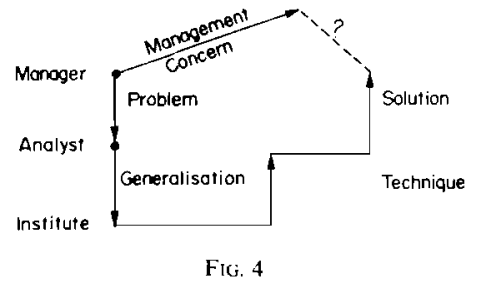

direct contact with management but within that framework. There is a double lesson here. Not only is this the only satisfactory way for us to operate in the long run, there are also implications for our 'customers', whether in Government, or in industry. Unless there is a strong group of people in the organisation already in contact with management who are able to absorb the ideas of the research group and apply them in the new situation, application will be almost impossible. I believe very strongly that the key to effective use by management of ORASA is in the existence of a strong 'in-house' ORASA type activity. We cannot substitute that relationship from an international Research Institute.

I have placed these, and subsequent remarks, in the IIASA context quite deliberately -it is necessary that you should understand our problems as well as our strengths. But do not miss the general import of what I have been saying. I have made some fundamental assertions about effective ORASA and the management/analyst relationship. I have also made some rather fundamental statements which are relevant to the role of the O.R. consultant and to the shape and organisation of O.R. research. I shall return to all these issues at a later stage.

\section{WHAT KIND OF RESEARCH?}

This is not a question with an obvious answer. When I first discussed the question of an Institute of O.R. Research some years ago ${ }^{1}$ I got warm support for the idea, but few positive suggestions as to what we should do. I subsequently conceived the idea that the information was there, but I was simply not asking the right questions. If you talked to successful O.R. managers you found that there were many problems that they were unable to tackle. Sometimes this was for organisational reasons or questions of internal politics. Quite often it was because the means were not yet available to them and that it was too big an investment for any one organisation to try and break the new ground on its own. So, one way of answering the question was to turn it on myself. As a result of this approach, I eventually identified six major problem areas where ORASA ought to be able to make a substantial impact, where currently the advice available to management was inadequate. These were as follows:

\section{(a) The munagement of complex programmes}

The management of a complex programme, whether we consider the construction of a complex plant or a regional development programme, would be a relatively straightforward question if it could be considered as a static operation. But it is not. Failures to

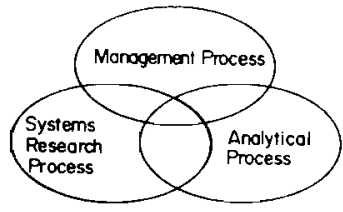

(a)

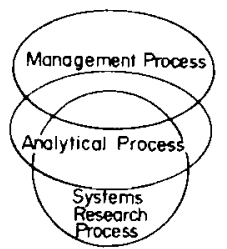

(b)

FiG. 5 
complete elements of the programme on time provide the smallest difficulties. Changes in assumptions, new information, changed organisation, etc., etc. all lead to situations where O.R. and systems analysis prove much less effective than one might have hoped. It should be possible to improve our effectiveness, but how?

\section{(b) Innovation}

The innovation problem is difficult in all industries. In the National Coal Board, we have been looking for years to see where the next great technological breakthrough was coming from, and how we could best develop existing ideas to general implementation. Other industries pave similar problems. But national governments are concerned as well. The need for more and better analysis seemed quite universal.

\section{(c) The problem of scale}

Once more I started with my own experience. One of the earliest decisions made in the process of planning a new colliery was its size, but the methodology for doing this did not appear to be adequate. Then I noticed that this was a universal problem. All around you find mistakes on scale--from hospitals to electricity generating units. At the moment, the mistakes of being too big are the most eye-catching. but mistakes in the other direction are probably as frequent. Surprisingly no standard method of approaching such problems is available which puts together at that time the work of the economists. the technologists and the sociologists.

\section{(d) Man/computer interaction}

Computers have been around for a long time, but microelectronics are transforming the situation again. Up to the present the computer has had little effect on the discretionary work of management. It provides more (or sometimes less!) information; it undertakes elaborate calculations; but management behaviour is hardly altered. The question is whether that situation will alter when computers, and information storage, are so cheap that every manager can have his own data bank-with his own clerk undertaking calculations at his bidding. It could cause a managerial revolution, with major consequences for training and organisation. What will the constraints be in the new situation?

\section{(e) Value and risk}

Decision-making under uncertainty has, for many years, been a familiar phrase in the O.R. world. When, however, one looks at the methods available they are of rather limited application. We have little idea how to evaluate risk or incorporate qualitative value judgements into the analysis - and this leaves the way open to others who are not afraid to venture into difficult waters, even though their available tools are little better formed---if at all. When it comes to the processes involved in coping with the negotiations involved in planning and managing potentially dangerous technological activities the situation becomes really difficult.

\section{(f) Management/analyst interface}

How can we develop our understanding of the processes by which change is induced in organisations?

That is one list, which I was forced to prepare in development of the Management and Technology Area at IIASA. But if ORASA as a subject is to develop--by which I mean tackling more and more difficult problems, not simply being cleverer at the old ones-we all ought to have a similar list and we ought to be pushing it towards our research colleagues. Do not blame the universities for not tackling the right problems unless you are willing to say what they are and have expressed a willingness to help them undertake the necessary work.

Returning to IIASA. The list of six research topics has stood the test of time, and remains the basis of the current MMT programme which currently includes three major research projects, three exploratory studies, and two industry studies. 


\section{Journal of the Operational Research Society Vol. 31, No. 6}

The first project of major research is in the field of Innovation, where we are looking at three nain questions: (1) How does a government decide on the best technological areas to encourage innovation? (2) How does it achieve the sort of changes it wants- what instruments are available to it, and how effective are they? (3) Within the firm or industry, what are the factors encouraging or preventing innovation?

The second main problem towards which substantial research effort is directed is the problem of scale. We have had a recent conference, which will be reported on in 1980 , which was the first time that technologists, economists and social scientists have been able to get together and talk about the topic. It was a lively debate right through to the end, and it was clear that no general approach was yet in sight. We will study particular problems of scale in different industries, and are thinking in terms of a handbook.

The third main research topic is the management of high risk situations. We have done previous work looking at the institutional and organisational problems associated with the Bravo oil blowout in the North Sea. We are currently organising a conference on institutional problems that arise in the contingency planning related to nuclear reactor safety. We are starting work on similar problems related to LNG and LPG plants. Overall we see this work in the wider context mentioned above, and have confidence in developing a major activity.

I shall not refer to all of the exploratory studies in detail. One is concerned with the impact of small scale computer systems on management, one with the use of operational gaming as an aid to policy-making, and one with aspects of the management of major regional programmes. To complete the picture we have also initiated some industry studies under the general title "Issues for the Eighties". These are collaborative research studies with representatives from one industry in the many countries involved in IIASA. The first two industries are coal and forestry.

It is too early to draw particular conclusions from the work itself, which has only just started, but there are certain general conclusions that can be drawn immediately. In the first place the establishment of research like this takes time. It is 2 years since the planning was begun, and it is only now that a full team has been established, working together and making real progress. Secondly, there seems to be a very general recognition of the fact that these topics are important and need research; so I am encouraged that the search process of identifying gaps in our analytical abilities was on the right lines. Finally, I find that although the projects chosen seem quite distinct, it is in fact almost impossible to keep them apart. They all lie close to the heart of management uncertainty at the present time, and they interact all the way. It is impossible, and even absurd, to tackle individual management problems in isolation. The moment we try to do this we are lost.

\section{WHO DOES IT?}

A determination to go forward, combined with an understanding of where and how to go, leave you exactly where you are unless you have the people to do the work. What kind of people are needed for such research? When we try to answer these questions in the IIASA context, there are certain background constraints which we have to consider. One of these is the fact that most people come to IIASA for one or two-year secondments (although we are trying to get more people to stay for longer). This has a major impact on project planning, bearing in mind the fact that no researcher will exactly follow the path of the person he succeeds, even if he comes from the same country and has the same scientific training! Secondly, it is necessary to realise that a move to Vienna is a major upheaval in the life of the scientist concerned, and of his family, and is only possible at certain moments in a person's career. To find the right persons, at the right time in their career and at the right time for their family is a major task. Finally, we find that not all people with the right qualifications fit into the IIASA environment. So our recruitment lead times are long and have a high variance, with always a finite possibility of 'non-appearance'. It makes team-building a nightmare. Even so, there are fundamental 


\section{Rolfe Tomlinson-Doing Something About the Future}

questions to be answered. For example, what kind of skills are we looking for? When I went to IIASA, I was quite clear that what I wanted was more operational research people, as we understood the phrase in the U.K. (And I was aware that Operations Research was something quite different, and that many other countries would use different names for the same thing.) The team that has now been assembled does not match that belief. The following is a list of all research staff who have worked for a period of a month or more in the Management and Technology Area during 1979-giving their nationality and academic discipline. They are:

\begin{tabular}{ll}
\hline Discipline & Nationality \\
\hline Management Scientist & Canada \\
Control Engineer & Japan \\
Psychiatrist & U.S.A. \\
Scientific Administrator & U.S.S.R. \\
Control Engineer & Finland \\
Decision Analyst & U.S.A. \\
Explosions Chemist & U.K. \\
Engineer & Sweden \\
Social Psychologist & Netherlands \\
Mathematician & U.S.A. \\
O.R. Man & U.K. \\
2 Economists & G.D.R. \\
Systems Dynamicist & U.S.A. \\
Mathematician & Austria \\
Nuclear Engineer & U.K. \\
Space Engineer & U.S.A. \\
Mining Engineer & Czechoslovakia \\
Economist & U.S.A. \\
Health Scientist & U.S.A. \\
Agriculturalist & Denmark \\
Mining Engineer & Poland \\
\hline
\end{tabular}

If you look back through that list, you will find that there is just one management scientist, from Canada, and one operational research man, from the U.K. How does this link in with what I thought before?

One reason, as I have said, is that there is no accepted name on a world wide basis to describe the kind of problem oriented, cross-disciplinary systems thinker-which is the basic characteristic of the traditional operational research person from the U.K. - or as I would now say the ORASA analyst. You have to find them where you can. A second reason is that we have encountered a need for a genuinely interdisciplinary approach. ORASA may be thought of as an interdisciplinary subject, but the analyst cannot be expert in all fields of knowledge. If you are breaking into new problem areas, you must sometimes reach out to the limits of existing knowledge-i.e. the disciplinary experts have to be involved. So, IIASA has taken me back to the origins of operational research. One needs disciplinary skills, but must somewhow avoid the restriction on inventive thought that these skills usually bring with them.

So I do not believe that one person (operational researcher, systems analyst, cybernetician) can, in himself, be fully interdisciplinary-though I believe more strongly than ever in the efficacy of the systems oriented, interdisciplinary approach to real life problem solving. (It is no coincidence that many of the most successful scientists at IIASA have had two quite different disciplinary careers.) Increasingly, I think that the O.R./systems role is to provide the methodological (in the broad, philosophical sense of the word) heart to such interdisciplinary studies. This is a traditional role, but one that is too often forgotten in our training courses in O.R. I have also discovered again that there are, happily, specialists who are able to throw off their disciplinary shackles when they have to. (Yet another reason for resisting attempts to make O.R. an "exclusive" profession.)

This list of people therefore represents a deliberate choice which gives a pointer for future thinking on what we do and how we teach it. Operational Researchers and Systems Analysts have to start thinking about their claim to be a central and essential 
part of it. By and large that claim has not yet been accepted, partly because it has not been made, partly because too many of the visible members of the community are showing all the traditional signs of exclusiveness and reductionism that is the antithesis on the systems movement.

\section{CONCLUSIONS}

In conclusion, let us come back to the title of the talk "Doing Something About the Future", by reiterating four points.

The first of these is to point out that in O.R. in the U.K. we start off from well prepared. firm ground. We have our failures and trauma; we are continually tempted down false paths; BUT, we have a proud record of achievement and some very exciting things are happening on the ground. It is time we were prepared to confound criticism by arguing our case in public. A number of our in-house teams have developed a sophisticated working relationship with managers in their organisations which is incredible to those who have learnt about O.R. from the literature. Too many people still believe that O.R. is an academic subject, undertaken in back rooms and universities. It is certainly not yet understood as "articulate intervention"- a cooperative venture with management. And how should it be known in this way if we do not tell them! It is worth while spending the time to write up our practical work-not to claim the millions of pounds saved, but to show the methodology, the intellectual excitement, and the systems sophistication involved. Unless we recognise the solid ground that we stand on, how can we persuade anyone else?

The second point is that, in ORASA, going forward is a necessary condition for survival. Our pride in the past gives us the opportunity for the future, but it does not secure it. In that sense Ackoff is right. We have to change and adapt if others are not to inherit our birthright. We shall have to tackle new kinds of problem, and develop the methodology to do so. I have been trying to urge the need for more positive, concerned, thinking in this respect for years. If you want a future you have got to make it.

Thirdly, the future should not be thought of as a mere extrapolation of the past. We need to think how to be involved in, and encourage, interdisciplinary studies into some of the big problems of the kind that we are tackling at IIASA. Our concern must not be vague and general; not general worries about the energy situation, for example, but particular problems facing government and industry for which-for one reason or another-little or no systems work is currently available. We are uniquely experienced in handling interdisciplinary problems in our organisations, where we have to work with every function in the firm or department. But we are little experienced in the research field. We cannot do this alone, so how do we collaborate?

Fourth, if we want to make a collaborative, original future it needs effort as much as thought. I can see no reason why we should not be as influential in raising funds, in supporting our good causes, as anyone else. It needs all those things necessary for survival; above all, will and determination. We have a head start. What are we waiting for?

\section{REFERENCES}

${ }^{1}$ R. C. TOMLINSON (1974) O.R. Is. Inaugural address as President of the Operational Research Society. Opl Res. Q. 25, 347-360.

${ }^{2}$ R. C. Tomlinson and G. H. MITChell (1978) Six principles for effective O.R.-their basis in practice. In $O . R$. $7 K$ (K. B. Haley, Ed.). North Holland, Amsterdam.

${ }^{3}$ R. C. TOMLinson (1977) Operational research and systems analysis-from practice to precept. Phil. Trans. $R$. Soc. A287, 355-371.

${ }^{4}$ R. C. Tomlinson (1979) Some dangerous misconceplions concerning operational research and applied systems analysis. Closing plenary lecture at the Third European Conference for Operarional Research (EURO III), Amsterdam, Netherlands, April 9-11

'R. L. Ackofr (1979) The future of operational research is past. J. Opl Res. 30, 9.3-104.

"R. L. AckofF (1979) Resurrecling the future of operational research.J. Op/ Res. Soc. 30, 189-199.

${ }^{7}$ N. ToBin, K. Rapl.eY and W. Teather (1980) The changing role of O.R. J. Opt Res. Soc. 31, 279-288.

*H. B(M)IHR(YY) (1978) Articulate Interiention. Taylor \& Francis, London. 